Bevista Eletrônica

REF - ISSN 1808-0804 Vol. VI (3), 70 - 80, 2009

\title{
CARACTERIZAÇÃo DE UM ISOLADO DE Trypanosoma cruzi OBTIDO DE UM PACIENTE CHAGÁSICO COM COMPROMETIMENTO CARDÍACO E DIGESTIVO
}

Characterization of an isolated of trypanosoma cruzi obtained of a chagasic patient with heart and digestive compromising

\section{Nozelmar Borges de Souza Júnior1; Kleber Mirallia de Oliveira1; Sara Dayane Santos; Fabiana Ribeiro da Mata1; João Roberto da Mata1}

${ }^{1}$ Laboratório de Doença de Chagas do Departamento de Morfologia do Instituto de Ciências Biológicas (ICB III) da Universidade Federal de Goiás Campus Samambaia Cep 7401/970; Caixa Postal - 131; Universidade Federal de Goiás - Goiânia - Goiás.

Autor para correspondência: jrdamata@pop.com.br

Recebido em 28/01/2009 - Aceito em 10/03/2009

RESUMO: A doença de Chagas é considerada atualmente negligenciada e sem terapêutica com eficiência completa, o que tem incentivado a pesquisa básica. Neste trabalho objetivou-se a caracterização de um isolado de Trypanosoma cruzi obtido num paciente portador da forma cardíaca e digestiva desta doença, no Hospital das Clínicas da Universidade Federal de Goiás. Inoculou-se 40 camundongos aos 15 e 60 dias de idade com $5 \times 10^{3}$ ou $5 \times 10^{4}$ tripomastigotas/animal. A parasitemia foi analisada e outros animais foram sacrificados e fixados com parafomaldeido. Fragmentos do encéfalo, coração, pulmão, língua, esôfago, estomago, rim, bexiga, intestino delgado e grosso foram incluídos em parafina, seccionados e corados com hematoxilina/eosina. Animais submetidos ao maior inóculo apresentaram ganhos de pesos menores e valores parasitêmicos mais elevados. Ocorreu parasitismo cardíaco, processo inflamatório focal ou difuso com raras alterações nos outros órgãos e ausência de mortes sugerindo a classificação deste isolado como cepa do tipo III.

PALAVRAS-CHAVES:Sistema digestivo, coração Trypanosoma cruzi. 
Mata, J. R. et al./Revista Eletrônica de Farmácia Vol 6(3), 70-80, 2009.

ABSTRACT: The Chagas disease is considered now neglectful and without therapeutics with efficiency completes what has been motivating the basic research. In this work the characterization of an isolated of Trypanosoma cruzi was aimed at obtained in a patient bearer in the heart and digestive way of this disease in the Clinics Hospital, Federal University of Goiás. It was inoculated 40 mice to the 15 and 60 days of age with $5 \times 103$ or $5 \times 104$ trypomastigotes for animal. The parasitemia was analyzed and other animals were sacrificed and fastened with formic aldehyde. Fragments of the encephalon, heart, lung, tongue, esophagus, stomach, kidney, bladder, small and thick intestine were included in paraffin, split up and red-faced with hematoxilin/eosin. Animals submitted to the largest inoculate presented won of smaller weights and values higher parasitize. It happened heart parasitism, focal lawsuit or diffuse, rare alterations in the other analyzed organs and absence of deaths suggesting the classification of this isolated as stump of the type III.

KEY-WORDS: Digestive system, heart, Trypanosoma cruzi. 
Mata, J. R. et al./Revista Eletrônica de Farmácia Vol 6(3), 70-80, 2009.

\section{INTRODUÇÃO}

A doença de Chagas descrita primeiramente em 1909 por Carlos Chagas (CHAGAS, 1909), ainda constitui um problema de saúde pública sendo considerada como uma doença negligenciada (DDNi, 2006). Ao longo de quase um século, esta moléstia tem sido um desafio aos pesquisadores que buscam tratamento eficiente sem, contudo lograr êxito completo (DIAS et al, 1997). A pesquisa básica em doença de Chagas tem recebido grande incentivo já que aproximadamente 11 milhões de pessoas estão contaminados (GÜRTLER et al., 2007) sendo cinco milhões apenas no Brasil (SOUZA et al., 2008).

Cepa é uma população derivada de um isolado de Trypanosoma cruzi ( $T$. cruzi) mantida em laboratório sob reprodução contínua por passagens seriadas em animais de laboratório (LUMSDEN, 1970). As diferentes cepas de $T$. cruzi determinam alterações anatomohistológicas com características distintas exibindo variado grau de tropismo tecidual (MELO \& BRNER, 1978). Para caracterizar os diversos isolados de $T$. cruzi vários parâmetros têm sido usados, tais como a virulência, curvas de parasitemia, morfologia do parasito no sangue periférico, tropismo tecidual, quadro histopatológico da infecção no camundongo. Estes parâmetros suportaram a classificações do $T$, cruzi em cepa tipo I (alta virulência e mortalidade para camundongos); cepa tipo II (virulência média com lesões predominantes cardíacas) e aquelas de baixa virulência com tropismo para tecido muscular como cepa do tipo III (ANDRADE \& ANDRADE, 1979).

Este trabalho teve como objetivo a caracterização, através do curso da doença em camundongos, de um isolado de $T$. cruzi obtido de um paciente portador da forma cardíaca e digestiva da doença de Chagas, no Hospital das Clínicas (HC) da Universidade Federal de Goiás (OLIVEIRA et al, 1993).

\section{MATERIAL E MÉTODOS}

Foram utilizados 40 camundongos machos B10A com 15 e 60 dias de idade fornecidos pelo Biotério do Instituto de Patologia Tropical e Saúde Pública (IPTESP) da UFG. Os animais foram infectados com um isolado de $T$. cruzi, obtido de um paciente do HC/UFG portador da forma cardíaca e digestiva da doença de Chagas. Os animais foram inoculados intraperitonealmente com $5 \times 10^{3}$ ou $5 \times 10^{4}$ tripomastigotas/animal e permaneceu no Biotério do laboratório de Bioquímica e Neurociências, do Instituto de Ciências Biológicas da Universidade Federal de Goiás recebendo água e ração (labina-purina) a vontade durante todo o experimento. Os animais constituíram os seguintes grupos contendo cinco animais cada.

Grupos A - 15 dias de idade

$1 \mathrm{~A}$ - Controle

$2 \mathrm{~A}$ - Análise Histológica - $5 \times 10^{3}$ tripomastigotas/animal

$3 \mathrm{~A}$ - Análise Histológica - $5 \times 10^{4}$ tripomastigotas/animal

GRUPOS B - 60 dias idade

$$
\text { 1B - Controle }
$$

2B - Parasitemia $\quad \begin{array}{lllll}-5 & \times & 10^{3}\end{array}$ tripomastigotas/animal

$3 B$ - Análise Histológica - $5 \times 10^{3}$ tripomastigotas/animal 
Mata, J. R. et al./Revista Eletrônica de Farmácia Vol 6(3), 70-80, 2009.

4B - Parasitemia - $\quad 5 \times \quad 10^{4}$ tripomastigotas/animal

5B - Análise Histológica - $5 \times 10^{4}$ tripomastigotas/animal

A parasitemia foi verificada pela análise microscópica (400X) e a contagem realizada em dias alternados a partir do terceiro dia da inoculação dos parasitos. Foram contadas as formas tripomastigotas em $5 \mu$ de sangue obtido pela secção da cauda do animal.

Os animais destinados à análise histológica foram sacrificados e fixados através de perfusão intracardíaca de parafomaldeido a $4 \%$ em tampão fosfato $0,1 \mathrm{M} ; \mathrm{pH} 7,2$. Foi retirado o encéfalo, coração, pulmão, língua, esôfago, estomago, intestino delgado e grosso, rim e bexiga. Fragmentos destes órgãos foram processados e incluídos em parafina (Histosec).
O material foi seccionado, corado com hematoxilina e eosina e analisado sob microscopia de luz.

\section{RESULTADOS}

Durante o período de 23 dias de infecção, o grupo de animais inoculados aos 15 dias de idade, com $5 \times 10^{3}$ tripomastigotas/animal, apresentou ganhos de pesos semelhantes aos do grupo controle. Já o grupo de animais inoculados com $5 \times 10^{4}$ tripomastigotas/animal, apresentou ganho de peso menor que os animais controles, assim como pelo grupo de $\begin{array}{lllll}\text { animais inoculados com } 5 \times & 10^{3}\end{array}$ tripomastigotas/animal (Tabela

Tabela 1. Valores médios do peso corporal em gramas (média \pm desvio padrão) de camundongos inoculados com Trypanosoma cruzi aos 15 dias de idade, com $5 \times 10^{3}$ ou $5 \times 10^{4}$ tripomastigotas/animal, e sacrificados aos 38 dias de idade (23 dias de inoculação). Valores máximos e mínimos entre parênteses.

\begin{tabular}{ccccc}
\hline Idade & Grupos & Inóculo & \multicolumn{2}{c}{ Peso médio dos animais } \\
\cline { 3 - 5 } & & & $\begin{array}{c}\text { Dia da inoculação } \\
(15 \text { dias de idade })\end{array}$ & $\begin{array}{c}\text { Dia do sacrifício } \\
(38 \text { dias de idade })\end{array}$ \\
\cline { 3 - 5 } 15 & & & $13,28 \pm 0,6(12,20-$ & $23,38 \pm 1,3(21,80-$ \\
dias & & $14,00)$ & $25,00)^{\mathrm{a}}$ \\
\cline { 2 - 5 } & & & $13,34 \pm 0,4(12,80-$ & $20,04 \pm 0,8(18,90-$ \\
& & & $13,80)$ & $20,09)^{\mathrm{b}}$ \\
\cline { 2 - 5 } & & & $13,50 \pm 0,9(12,60-$ & $23,14 \pm 1,8(20,40-$ \\
& & & $15,00)$ & $25,30)^{\mathrm{a}}$
\end{tabular}

Os valores com letras diferentes na coluna indicam diferenças significativas (Anova).

Os valores da parasitemia foram obtidos em animais infectados aos 60 dias de idade. 0 Inóculo de $5 \times 10^{3}$ tripomastigotas/animal aos 60 dias de idade, induziu curva parasitêmica com início no 90 dia, pico máximo no $25^{\circ}$ dia após a inoculação e término do período de parasitemia no 590 dia, com valor da parasitemia médio no pico de $1.311,18$ tripomastigotas por $5 \mu \mathrm{l}$ de sangue. A inoculação de $5 \times 10^{4}$ tripomastigotas/animal aos 60 dias 
Mata, J. R. et al./Revista Eletrônica de Farmácia Vol 6(3), 70-80, 2009.

de idade induziu curva parasitêmica com início parasitêmicos médios no pico foram no 30 dia de infecção, pico no 130 dia de infecção com valor parasitêmico médio no pico de 4.252,93 e término da parasitemia patente significativamente maiores quando se aumentou 0 inóculo de $5 \times 10^{3}$ para $5 \times 10^{4}$ tripomastigotas/animal

(Figura

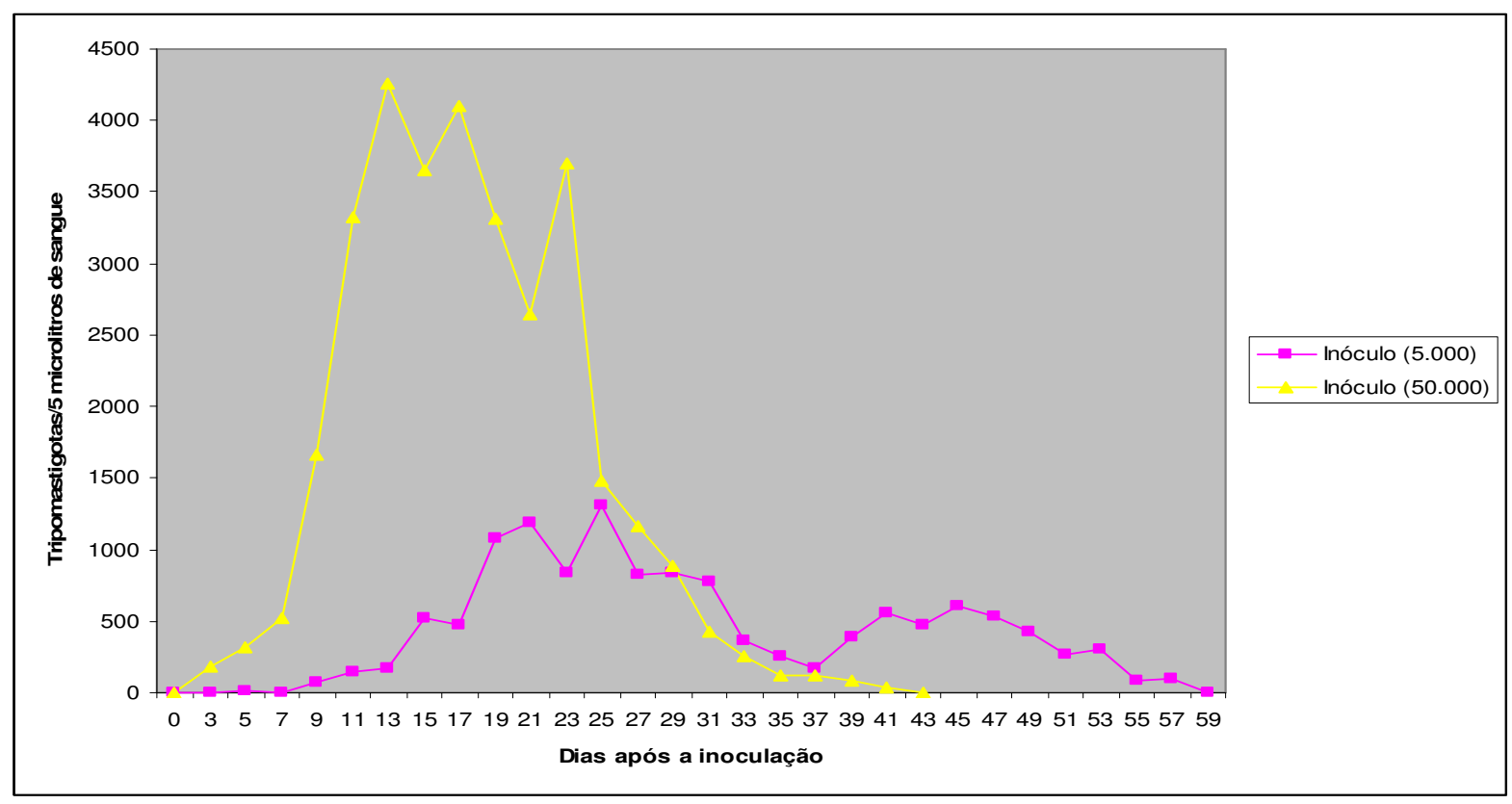

Figura 1. Curva de parasitemia (valores médios) em camundongos $B 10 A$ infectados com o inóculo de $5 \times 10^{3}$ ou $5 \times 10^{4}$ tripomastigotas/animal do Trypanosoma cruzi aos 60 dias de idade.

O isolado do T. cruzi, com ambos os inóculos e em ambas as idades, foi capaz de induzir parasitismo cardíaco. Os animais infectados aos 15 dias de idade ou aos 60 dias apresentaram ninhos de amastigotas no miocárdio (Figura 2-A). Ocorreu a presença de processo inflamatório focal em ninho de amastigotas rompido (Figura 2-B) e infiltrados inflamatórios perivasculares (Figura 2-C).
Ocasionalmente foram encontrados focos inflamatórios distribuídos tanto nas regiões endocárdicas quanto nas subepicárdicas (Figura 2-D). Processo inflamatório difuso de intensidade leve foi encontrado na língua. Para todas as idades e inóculos, não houve comprometimento da musculatura lisa do esôfago e dos demais órgãos com ausência de reação inflamatória. 

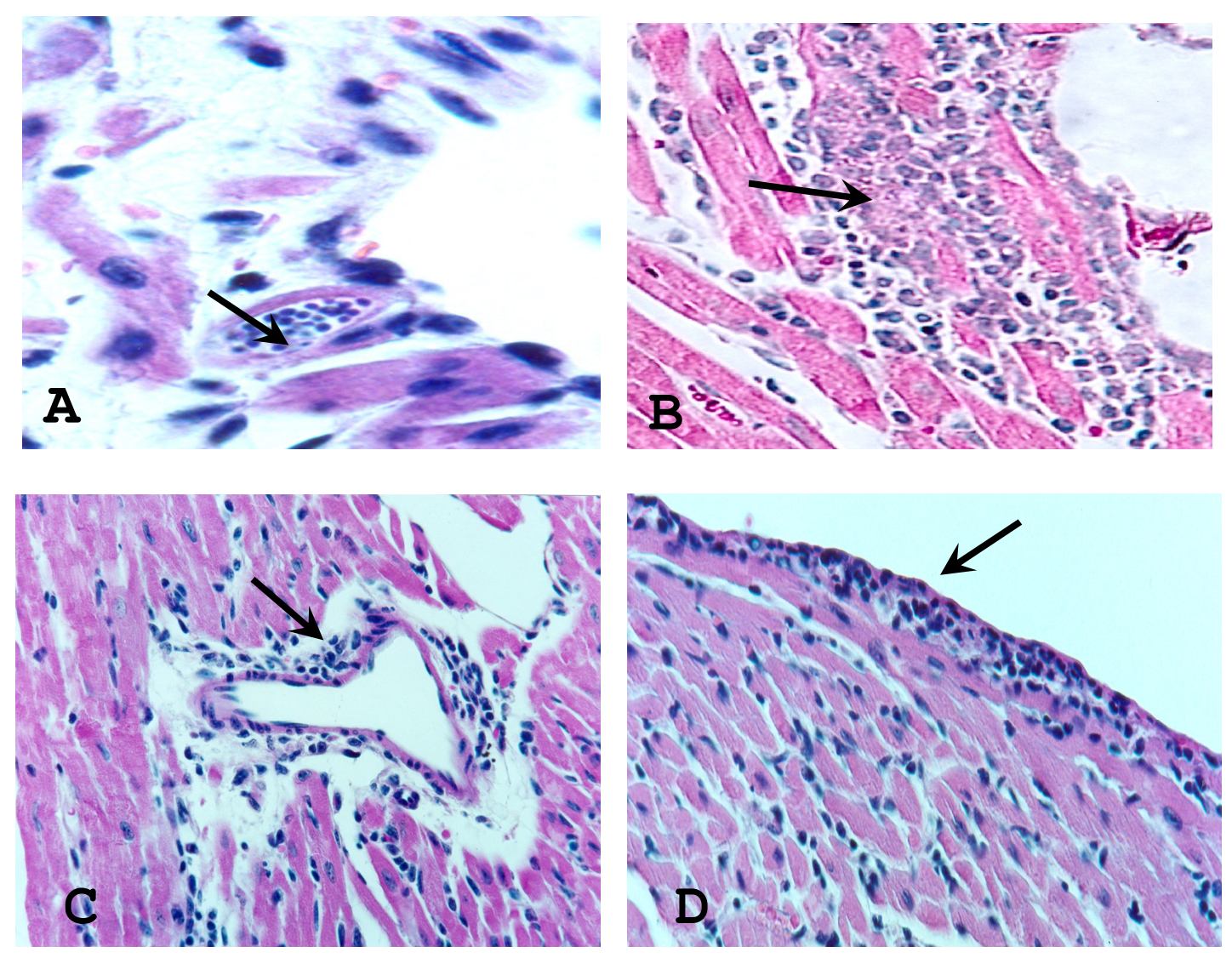

Figura 2. Fotomicrografia do miocárdio do ventrículo esquerdo de camundongos inoculados com 5x $10^{4}$ tripomastigotas/animal inoculados aos 60 ou 15 dias de idade coradas com Hematoxilina/eosina.

A - inóculo (60 dias). Ninho íntegro de amastigotas (seta). 800X

$B$ - inóculo (15 dias). Ninho rompido com processo inflamatório intenso (seta). 600X

C - inóculo (15 dias). Infiltrado inflamatório perivascular (seta). 450X

D - inóculo (60 dias). Processo inflamatório Subepicárdico (seta). 450X

O aumento do inóculo de $5 \times 10^{3}$ para $5 \times$ $10^{4}$ tripomastigotas/animal determinou aumento significativo do número de infiltrados perivasculares nos animais inoculados aos 60 dias de idade. Os animais mais jovens submetidos aos mesmos inóculos apresentaram maior número de infiltrado perivascular. 0 número de processos inflamatórios focais foram maiores em animais mais jovens (15 dias) e submetidos ao maior inóculo (Tabela 2).

Tabela 2. Número médio (média \pm desvio padrão) de processo inflamatório focal no coração de camundongos inoculados aos 15 ou 60 dias de idade, com $5 \times 10^{3}$ ou $5 \times 10^{4}$ tripomastigotas/animal, do Trypanosoma cruzi. Valores máximos e mínimos entre parênteses.

\begin{tabular}{ll}
\hline \multirow{2}{*}{$\begin{array}{c}\text { Idade dos } \\
\text { animais }\end{array}$} & $\frac{\text { Tamanho do inóculo / Número de processo inflamatório focal }}{5 \times 10^{3}}$ \\
\end{tabular}


Mata, J. R. et al./Revista Eletrônica de Farmácia Vol 6(3), 70-80, 2009.

\begin{tabular}{ccc}
\hline 15 dias & $45,20 \pm 10,08(30-56)^{\mathrm{a}}$ & $63,60 \pm 25,18(38-100)^{\mathrm{c}}$ \\
\hline 60 dias & $37,25 \pm 2,21(35-40)^{\mathrm{b}}$ & $50,60 \pm 21,25(20-77)^{\mathrm{d}}$
\end{tabular}

Os valores com letras diferentes nas colunas e linhas indicam diferenças significativas. (anova).

\section{DISCUSSÃo}

Apesar de Carlos Chagas ter identificado o T. cruzi em 1909, somente na década de 40 é que o problema da doença de Chagas começou a ser reconhecido no Brasil (DIAS \& COURA, 1997). O grande número de infectados (WANDERLEY, 1994; CAROD-ARTRAL et al, 2003; GÜRTLER et al., 2007; SOUZA et al., 2008), torna essa doença um importante problema de saúde pública. Ainda não há tratamento com eficácia total e a patogênese da doença de chagas não é compreendida por completo justificando a necessidade de mais pesquisas básicas (DDNi, 2006). Neste sentido empreendeu-se a caracterização de alguns aspectos de mais este isolado de $T$. cruzi.

Dentre os diversos fatores que influenciam o curso da doença de Chagas num modelo experimental, estão os que dependem do parasito e outros inerentes ao hospedeiro (COSSIO et al, 1974). Procuraram-se explorar alguns destes aspectos ao variar o tamanho do inóculo e a idade do animal. A amostra de $T$. cruzi utilizada induziu parasitismo de intensidades diferentes dentre os órgãos estudados, o que confirma outros relatos (OLIVEIRA et al, 1993) ao observar o mesmo comportamento para este isolado.

Este isolado demonstrou picos parasitêmicos com inóculo de $5 \times 10^{4}$ aos 13 dias característicos de cepa tipo II, porém com inóculo de $5 \times 10^{3}$ o pico ocorreu aos 25 dias caracterizando cepa do tipo III. Foram verificadas lesões teciduais no coração, focais ou difusas com raro comprometimento dos outros órgãos e ausência de mortes durante todo o experimento, mesmo sob o inóculo mais alto. Apesar de um dos picos parasitêmicos se apresentarem abaixo de 20 dias (cepa I e II) e não se observar lesões predominantes de musculatura esqueléticas (cepa III), as lesões cardíacas não induziram prejuízos graves na sua fisiologia, demonstrada pela sobrevivência de todos os animais infectados. Estes parâmetros, tomados em conjunto, sugere a classificação deste isolado como cepa do tipo III (ANDRADE \& ANDRADE, 1979).

Os animais inoculados com $5 \times 10^{4}$ tripomastigotas/animal apresentaram ganho de peso do $15^{\circ}$ até o momento do sacrifício aos $38^{\circ}$ dias de idade, sendo este menor que o demonstrado pelos animais controles. Estes dados coadunam com a desaceleração de ganho de peso induzida pela infecção chagásica, utilizando a cepa $\mathrm{Y}$ (OLIVEIRA et al, 1986; MELO \& MACHADO, 2001). Do mesmo modo, se assemelha com outros dados (DA MATA, 2002) ao inocular este mesmo isolado em camundongos, observou menor ganho de peso para os animais infectados em relação aos controles. A inoculação de $5 \times 10^{3}$ tripomastigotas/animal apresentou o mesmo ganho de peso em relação aos animais não infectados. Este fato sugere que o comprometimento do estado geral dos animais infectados, não foi suficientemente afetado em relação ao parâmetro ganho de peso. 
Mata, J. R. et al./Revista Eletrônica de Farmácia Vol 6(3), 70-80, 2009.

Animais com 60 dias de idades sob inóculo de $5 \times 10^{3}$ tripomastigotas/animal, apresentaram início de parasitemia no 90 dia com pico no $25^{\circ}$ dia e término no $43^{\circ}$ dia com ausência de mortes, porem usando a cepa $\mathrm{Y}$ em camundongos $\mathrm{C} 3 \mathrm{H}$ observou-se início de parasitemia no 90 dia de infecção com alta virulência e alto nível de mortalidade entre o $10^{\circ}$ e o $12^{\circ}$ dia. Quando se utilizou um inóculo dez vezes maior $\left(5 \times 10^{4}\right)$, ocorreu início de parasitemia no $3^{\circ} \mathrm{dia}$, pico no $13^{\circ} \mathrm{com}$ término no $43^{\circ}$ dia, demonstrando que o aumento do inóculo induziu pico parasitêmico mais precoce, semelhante a outro relato para este mesmo isolado de $T$. cruzi (OLIVEIRA et al, 1993). A mesma relação foi também verificada utilizando-se o mesmo isolado, constatando maior precocidade do pico parasitêmico quando se aumentou o inóculo de 4.000 para 200.000 tripomastigotas/animal (DA MATA, 2002).

\section{CONCLUSÕES}

A infecção por este isolado de T. cruzi em camundongos B10A induziu infiltrados perivasculares e processos inflamatórios focais ou difusos com intensidade de leve a
O parasitismo nos animais de 15 dias de idade foi maior do que naqueles de 60 dias, assemelhando as observações em animais infectados na primeira fase da vida pós-natal, (COSTA et al, 1986) assim como em crianças chagásicas (DIAS et al, 1985; PRATA, 1994). Este fato suporta que 0 maior inóculo combinado com a menor idade do animal, é capaz de induzir maior intensidade da infecção (MATA et al, 2002).

Camundongos infectados, sem mencionar o tipo de cepa, idade dos animais e o tamanho do inóculo, demonstraram parasitismo encefálico em todos os animais inoculados (SANÁBRIA, 1969) contrastando com o que se verificou neste trabalho e em outros relatos (PITTELLA et al, 1993; MATA et al, 2000).

moderada. As lesões teciduais foram primordialmente em músculo cardíaco e o curso da doença apresentou comportamento de cepa do tipo III. 
Mata, J. R. et al./Revista Eletrônica de Farmácia Vol 6(3), 70-80, 2009.

\section{REFERÊNCIAS BIBLIOGRÁFICAS}

ANDRADE, Z.A. \& ANDRADE, S.G. Trypanosoma cruzi e Doença de Chagas, 10 edição, Rio de Janeiro: Guanabara koogan, p. 214-218, 1979.

BRENER, Z.; ANDRADE, Z.A.; BARRAL-NETTO, M. Trypanosoma cruzi e doença de Chagas. $2^{\circ}$ edição, Rio de Janeiro: Guanabara Koogan, p. 431, 2000.

CAROD-ARTAL, F.J., MELO, A.P.; HORAN, T.A. American trypanosomiasis (Chagas'disease): na unrecognised cause of stroke. Journal of Neurology Neurosurgery and Psychiatry. v. 74, p. 516-518, 2003.

CHAGAS, C. Nova tripanozomiase humana. Estudo sobre a morfologia e o ciclo evolutivo do Schizotrypanum cruzi agente etiológico de nova entidade mórbida do homem. Memórias do Instituto Oswaldo Cruz, v. 1, p. 1-62, 1909.

COSSIO, P.M.; LAGUENS, R.P.; DIEZ, C.; SZARFMAN, A.; ARANA, R.M. Chagasic cardiopathy. Antibody reacting with plasma membrane of striated muscle and endothelial cells. Circulation, v. 50, p. $1250-1251,1974$.

COSTA, S.C.G.; CALABRESE, K.S.; ALENCAR, A.A.; LAGRANGE, P.H.; Trypanosoma cruzi invasion on structures related to development and central nervous system. Revista Brasileira de Neurolologia, v. 22, p. 183-190, 1986.

DA MATA, F.R. Alterações induzidas por Trypanosoma cruzi em camundongos: Influência do tamanho do inóculo, da idade e do estado imunológico do animal. 2002. 102p. Dissertação (Mestrado), Instituto de Ciências Biológicas, Universidade Federal de Goiás, Goiânia.

DDNi - Drugs for Neglected Diseases initiative. Simpósio - Descoberta e desenvolvimento de drogas para doença de Chagas e leishmanioses - Fiocruz/DNDi, Rio de Janeiro, 2006.

DIAS, J.C.P.; LOYOLA, C.C.P.; BRENER, S. Doença de Chagas em Minas Gerais: Situação atual e perspectivas. Revista Brasileira de Malariologia e Doenças Tropicais, v. 37, p. 7-28, 1985.

DIAS, J.C.P.; COURA, J.R. Epidemiologia. In: Clínica e Terapêutica da Doença de Chagas: uma abordagem prática para o clínico geral. $1^{0}$ edição, Rio de Janeiro: Fiocruz, p. 33-55. 1997.

DIAS, J.C.P.; SILVEIRA, A.C.; SCHOFIELD, C.J. The impact of Chagas Disease Control in Latin America-A Review. Memórias do Instituto Oswaldo Cruz, v. 97, p. 603 - 612, 2002. 
Mata, J. R. et al./Revista Eletrônica de Farmácia Vol 6(3), 70-80, 2009.

GÜRTLER, R.E. et al. Domestic dogs and cats as source of Trypanosoma cruzi infection in rural northwestern Argentina. Parasitology, v.134, p. 69-82, 2007.

LUMSDEN, W.H.R. Biological aspects of Trypanosomiais Research: Retrospect of the1965 at 1969, Advances parasitology, v. 8, p. 227 - 249, 1970.

MATA JR, CAMARGOS ERS, CHIARI E, MACHADO CRS. Trypanosoma cruzi infection and the rat central nervous system: proliferation of parasites in astrocytes, and the brain reaction to parasitism. Brain Research Bulletin, v. 53, p.153 - 162, 2000.

MELO, R.C.; BRENER, Z. Tissue tropism of diferent Trypanosoma cruzi strains. American Socyet Parasitologists, v. 64, p. $475-482,1978$.

MELO, R.C.; MACHADO, C.R. Trypanosoma cruzi: peripheral blood monocytes and heart macrophages in the resistance to acute experimental infection in rats. Experimental Parasitology, $\mathrm{v}$. 97, p. $15-23,2001$.

OLIVEIRA, J.S.M.; MUCCILO, G.; SCOZZAFAVE-NETO, F.; MAFFIA, L.G. Changes in myocardial norepinephrine levels in response to stress, exercise and aging in control and Trypanosoma cruziinfected rats. Brazilian Journal of Medical and Biological Research, v. 19, p. 367 - 374, 1986.

OLIVEIRA, E.C.; STEFANI, M.M.A.; LUQUETTI, A.O.; VÊNCIO, E.F.; MOREIRA, M.A.R.; SOUZA, C.; REZENDE, J.M. Trypanosoma cruzi and experimental chagas' disease: Characterization of a stock isolated from a patient with associated digestive and cardiac form. Revista da Sociedade Brasileira de Medicina Tropical, v. 26, p. 25 - 33, 1993.

PITTELlA, J. E.; MENEGUetTE, C.; BARBOSA, A.J. Histopathological and immunohistochemical study of the brain and heart chronic cardiac form of Chagas'disease. Arquivos de Neuro-psiquiatria, v. 51, p. $8-15,1993$.

PRATA, A. Chagas' disease. Infection Disease Clinical North American, v. 8, n. 1, p. 61 - 76, 1994.

SANÁBRIA, A. Nuevas investigaciones acerca de la ultrastructure e histoquímica del Trypanosoma cruzi en el cerebro del ratón. Acta Cient Venezolana, v. 20, p. 32 - 39, 1969.

SOUZA et al. Aspectos clínico-laboratoriais da infecção natural por Tripanosoma Cruzi em cães de Mato Grosso do Sul. Ciência Rural, Santa Maria, v.38, n.5, p.1351-1356, 2008. 
Mata, J. R. et al./Revista Eletrônica de Farmácia Vol 6(3), 70-80, 2009.

WANDERLEY, D.M.V. Epidemiologia da doença de Chagas. Revista da Sociedade de Cardiologia do Estado de São Paulo, v. 4, p. 77 - 84, 1994. 